\title{
DESIGUALDADE \\ E ASSOCIATIVISMO \\ Proximidade Espacial E DistânCIa SOCIAL \\ NA ConformaÇÃo da Sociedade Civil
}

\author{
Marcelo KunRath Silva \\ RUI Zanata JR.
}

\begin{abstract}
R E S U M O O objetivo deste ar tigo é analisar os efeitos das pr ofundas desigualdades que marcam a sociedade brasileira sobre a conformação da vida associativa nas grandes cidades, tendo por referência uma pesquisa empirica realizada com uma Associação de Moradores de um tradicional bairro de classe média de Porto Alegre. A partir do estudo das relações e da atuação desta entidade, percebe-se um alto grau de segmentação do tecido associativ o da cidade em decorrência das marcantes distâncias estruturais e relacionais entre seus moradores. Devido a esta segmentação, as entidades de classe média e alta tendem a estabelecer vínculos e desenolver açôes com atores que compar tilham posiçôes similar es no espaço social. A o mesmo tempo, tendem a não se relacionar com entidades popular es, mesmo que espacialmente próximas. E ste resultado indica que as desigualdades costumam se reproduzir nos processos associativos que conformam a sociedade civil brasileira, tema pouco abordado pela literatura dedicada ao tema.
\end{abstract}

P A L A V R A S - C H A V E Associativismo; sociedade civil; desigualdade; distância social; Porto Alegre.

\section{INTRODUÇÃO}

A caracterização do Brasil como um país marcado por desigualdades extremas é um aspecto que marca praticamente todas as interpretaçôes, acadêmicas ou não, sobre ele. Tal fato se expressa na proliferação de dicotomias (rural/urbano, atrasado/moderno, belíndia, entre outras) que tentaram, ao longo do tempo, apr eender a convivência de elementos profundamente desiguais dentro do mesmo espaço social. Curiosamente, no entanto, são poucos os estudos que, ao longo do tempo, se $\mathrm{v}$ oltaram para as implicações desta desi gualdade na conformação da sociedade civil brasileira. ${ }^{1}$

O objetivo deste ar tigo é analisar algumas destas implicações, tendo por $r$ eferência uma pesquisa empírica realizada com uma Associação de Moradores de Porto Alegre formada em um tradicional bairro de classe média da cidade. A partir do estudo das relações e da atuação desta entidade, percebe-se um alto grau de segmentação do tecido associativo da cidade em decorrência das marcantes distâncias sociais entre seus moradores. Devido a esta segmentação, as entidades de classe média e alta tendem a estabelecer vínculos e desenvolver ações com indivíduos, organizaçôes e instituições que compar tilham posiçôes similares no espaço social. Ao mesmo tempo, tendem a não se r elacionar com entidades populares, mesmo que estas estejam bastante próximas em termos espaciais.

Este resultado, mesmo que limitado pela fragilidade do supor te empírico oferecido por um estudo de caso e pelas especificidades do município de $\mathrm{P}$ orto Alegre frente à diversidade sociopolítica e urbanística das cidades brasileiras, fundamenta a hipótese de que

10 conceito de sociedade civil designa, neste artigo, o conjunto de práticas associativas existentes em um determinado contexto. Neste sentido, é empregado para apreender um conjunto amplo e diversificado de atores sociais, despido dos aspectos normativos que parte da literatura associa a este conceito. (Lavalle, 2003) 
as desigualdades tendem a se $\mathrm{r}$ eproduzir e operar nos pr ocessos associativos que conformam a sociedade civil no país. P roblematiza-se, desta forma, a generalização acrítica do argumento de que o associativismo civil teria um iner ente sentido e/ou efeito igualitário, tal como encontrado em certas correntes da literatura da sociedade civil e do capital social de inspiração neo-tocquevilliana.

\section{DESIGUALDADE E ASSOCIATIVISMO: PROBLEMATIZAÇÃO}

Conforme salientado acima, a r elação entre desigualdade e associativismo foi pouco analisada pela literatura brasileira. A maior par te dos trabalhos que enfocaram tal $r$ elação, no entanto, apresentaram uma tendência a se concentrar na análise dos efeitos da desigual dade no processo de engajamento associativ o. De um lado, nesta literatura pr edomina o argumento de que a desigualdade extr ema geraria significativos obstáculos ao engajamento associativo dos segmentos da sociedade brasileira ocupantes das posiçóes subalternas do espaço social. Tal argumento pode ser observado na conclusão de Reis, de que

a própria persistência e intensificação da desigualdade social cria desincentiv os ao associativismo, fortalece a descrença na política, e r eduz o escopo da identidade coletiv a. (...) Nessa situação, o mer cado político se contrai. Pobreza acentuada e níveis tão altos de privação relativa como os que temos, reduzem o incentivo para fazer parte da sociedade civil. (Reis, 1996, pp.449-50)

Em estudo recente, Santos (2006) trabalha com a mesma perspectiva, argumentando que a combinação de desigualdade extr ema, inércia social e incapacidade das instituições, ao garantirem os dir eitos constitucionais básicos, produz um contexto que desestimula o envolvimento associativo e a participação política. Como salienta o autor,

o custo do fracasso das açôes coletiv as pode ser bastante elev ado, com significativ a deterioração do status quo dos participantes, circunstância suficientemente ameaçadora para deprimir o ânimo r eivindicante dos mais necessitados. Ser pobre, no Brasil, é uma condição associada à altíssima taxa de av ersão ao risco e à opção por estratégias conser vadoras de sobrevivência. (Santos, 2006, p.180)

A desigualdade no acesso ao Estado, por sua v ez, é destacada por F erreira (1999) como um fator central no bloqueio do envolvimento associativo dos segmentos subalternos da sociedade brasileira. Para o autor, a alienação associativa seria uma

resposta de vastas parcelas da população à total ausência do aparato estatal no seu cotidiano. A desconfiança em relação à classe política, a cultura cívica pr edatória e a ausência de uma per cepção do Estado como provedor de bens coletivos básicos (...) sugerem que os entrevistados talvez nem ponderem os custos do contato pessoal com o político; os benefícios do ex ercício da política como r epresentação e defesa de interesses organizados devem ser mera ficção para a quase totalidade da população brasileira. (Ferreira, 1999, pp.99-100)

De outro lado, quando o foco da análise se dirige aos processos organizativos no extremo oposto da pirâmide social, obser va-se a tendência de enfatizar a fragilidade de tais processos frente à força e eficácia de mecanismos não coletiv os de encaminhamento de 
demandas. ${ }^{2} \mathrm{Na}$ medida em que a extrema desigualdade confere aos membros dos estratos superiores da sociedade uma posição privilegiada no acesso aos tomadores de decisões governamentais e na distribuição dos recursos sociais, haveria pouco estímulo aos processos organizativos entre estes segmentos. Tal argumento se expressa, por exemplo, na ênfase de Marques (1999) nas r elações interpessoais como mecanismo central de acesso ao Estado no Brasil. Segundo o autor, sua "investigação demonstra que a intermediação de inter esses no setor de política estudado [política de saneamento básico implantada pela empr esa estadual concessionária dos ser viços (a CEDAE) no Rio de Janeiro entre 1975 e 1996] ocorre de forma disseminada por inúmeros contatos pessoais entre integrantes do Estado e interesses privados, ao contrário do padrão característico nor te-americano de lobbies [...], ou do típico corporatismo social-democrata eur opeu". (Marques, 1999, pp.48-9)

No entanto, apesar desses obstáculos existentes ao engajamento associativo, corretamente destacados pelos autor es, é preciso ter presente que eles não são totalmente eficazes no bloqueio de tal engajamento. Ou seja, o seu reconhecimento não deve levar à conclusão de que eles pr oduziriam, inex oravelmente, uma sociedade completamente desorganizada e fragmentada. Ao contrário, a despeito de tais obstáculos, a sociedade brasileira passou, nas últimas décadas, por uma significativa ampliação e complexificação do seu tecido associativ o, claramente atestada por pesquisas $r$ ecentes (IBGE; IPEA; ABONG; GIFES, 2008).

Apesar desse associativismo em expansão ser objeto de div ersas pesquisas, as orientações teóricas predominantes dificultaram a análise de como a desigualdade incide sobre os processos organizativos e a atuação das organizações sociais. Em especial, a ênfase normativa no caráter igualitário e democratizante das organizaçōes da sociedade civil - que marcou tanto o campo de estudos sobr e movimentos sociais nos anos 1980, quanto o campo de estudos sobre sociedade civil e capital social em períodos mais r ecentes (Silva, 2006) - limitou a capacidade de problematizar a relação destas organizações com os processos de (re)produção das desigualdades no Brasil. Além disso, escolhas e limitações metodológicas do campo de estudos sobre sociedade civil tenderam a secundarizar ou a apresentar dificuldades de apr eender os pr ocessos organizativ os de setor es dominantes da sociedade brasileira, restringindo grande parte das análises aos processos de mobilização e organização dos setores subalternos e/ou contestadores.

Buscando superar essas limitações, este ar tigo pretende analisar os efeitos da desigualdade na configuração do tecido associativ o, tendo por fundamento o seguinte argumento de Kerstenetzky: "quando as desigualdades socioeconômicas são 'duráveis' e elevadas, é bem plausív el que se r epliquem no interior da vida associativ a, bem como entr e grupos organizados e não organizados, enfraquecendo a habilidade da inclusão política da participação associativa” (Kerstenetzky, 2003, p.132).

Mais especificamente, são abordadas as implicações das profundas distâncias sociais, geradas pelos altos nív eis de desigualdades existentes no país, sobr e a dinâmica associativa. Argumenta-se que estas distâncias criam barreiras que dificultam e, no limite, bloquei am o contato e a constituição de vínculos entr e indivíduos e gr upos ocupantes de posições desiguais na hierar quia social. $\mathrm{O} u$ seja, tenderia a ocorr er uma conjugação entr e distância estrutural e distância relacional, tal como definidas por Botter o:

\footnotetext{
nas perspectivas estruturais, grupos são definidos como socialmente distantes se eles são muito diferentes entre si (em termos de categorias de classe, gêner o ou raça), enquanto que nas perspectiv as relacionais eles são definidos como socialmente distantes se eles raramente seassociam entre si. Grupos podem
}

2 Uma exceção impor tante a esta tendência encontrase nos trabalhos de Dreifuss (1981; 1989). 
ser muito diferentes (pertencendo a diferentes categorias de classe ou raça), mas, ainda assim, serem socialmente próximos se eles se $\mathrm{r}$ elacionam por amizade ou por par ceria sexual regularmente. (Bottero, 2005, p.7)

A literatura que analisou o processo de urbanização brasileiro tradicionalmente destacou o processo de segregação socioespacial que o caracteriz ou e, sob outras r oupagens, ainda o caracteriza (Torres et al., 2003; Torres, 2004). Isso pode ser observado, de um lado, nos estudos sobr e a urbanização por expansão de periferias das décadas de 1970 e 1980 (Kowarick, 1979; Caldeira, 1984), e, de outr o, nas pesquisas recentes sobre a proliferação dos condomínios fechados nas cidades brasileiras (Caldeira, 2000; Alonso et al., 2009). Em ambos os casos, obser va-se uma tendência de combinação entr e segr egação territorial e social, gerando um espaço urbano mar cado pelo distanciamento espacial daqueles já socialmente distantes.

Sem negar a importância e a correção de tais interpretações, observa-se, no entanto, que as cidades brasileiras, em maior ou menor grau, tendem a apr esentar situaçōes de relativa proximidade espacial entre populações marcadamente desiguais em termos de seu posicionamento na estrutura social. Seja pela capacidade de resistência das populaçóes pobres aos processos de remoção e periferização, seja pelos limites da reprodução do modelo de deslocamento das classes altas para áreas habitadas unicamente por seus "iguais” (como no caso dos subúrbios de div ersas cidades norte-americanas), entre outros processos, produziu-se um espaço urbano que não é totalmente apr eendido pelo argumento da segregação socioespacial (Caldeira, 2000; Torres et al., 2003). De fato, como ilustra dramaticamente a configuração urbana da cidade do Rio de Janeiro, a proximidade espacial entre as ár eas habitadas por ricos e pobr es (o asfalto e a fav ela) constitui um elemento importante na estruturação do espaço urbano de muitas cidades brasileiras.

Qual o efeito da proximidade espacial sobre a configuração das relações entre os segmentos sociais profundamente desiguais que habitam estes espaços? E m que medida tal proximidade possibilita a superação da distância estr utural a par tir de uma convivência dos desiguais?

Em uma recente pesquisa sobre redes sociais e pobreza em São Paulo, Marques et al. (2007) demonstram que as distâncias sociais tendem a se $\mathrm{r}$ eproduzir com relativa independência do nív el de segr egação das ár eas habitadas pelas populações mais pobr es. $\mathrm{Ou}$ seja, mesmo moradores pobres de áreas integradas no espaço urbano, espacialmente próximos de áreas habitadas por populações com níveis mais elevados de renda, tendem a ter suas redes sociais marcadas pelo localismo e a homofilia. Como concluem os autor es,

podemos dizer que há forte localismo nessas redes analisadas - uma vez que a maioria das redes pessoais encontra-se fortemente estruturada em torno dos vínculos que ocorrem numa determinada área -, mas não foi observado impacto da segregação residencial sobre as formas de estruturação das redes pessoais, uma vez que as características gerais observadas estão presentes em contextos mais e menos segregados. (Marques et al., 2007, p.28)

Essa percepção sobre a reprodução das distâncias sociais apesar da pr oximidade espacial também é salientada pela pesquisa de Ribeiro (2008) no Rio de Janeiro. Examinando as relaçóes entre moradores de um conjunto habitacional popular e os morador es do bairro de classe média no qual o conjunto se localiza, o autor conclui que " o nosso estudo de caso evidencia que a pr oximidade territorial não implica necessariamente em co- 
habitação. Ela não garante a interação entre grupos sociais localizados em posições distantes do espaço social, mas apr oximados pela geografia" (Ribeiro, 2008, p.15).

Por fim, em um estudo sobre segregação residencial e relações de vizinhança em um bairro de Recife, Silva et al. (2007) identificam que, apesar da heter ogeneidade social do bairro, há um baix o grau de convivência entr e os segmentos per tencentes a posiçóes sociais distintas. Como concluem as autoras:

\footnotetext{
o caso de R ecife, e mais especificamente o bairr o de A pipucos, vem comprovar que a pr oximidade geográfica forte não é a única variável que deve ser levada em consideração quando consideramos a importância da vizinhança. Pois, assim como as difer enças sociais, as distâncias de contato e de convívio em Apipucos são também marcantes. (Silva et al., 2007, p.6)
}

Os resultados destas div ersas pesquisas ofer ecem, assim, supor te para o argumento de Silva e Bitoun (2006, p.43) de que "nesse padrão de segregação que vem se desenhando, as desigualdades são alocadas em espaços contíguos, muito próximos, mas, nem por isso, conexos ou menos extr emados e agressivos. De fato, a segr egação parece prescindir do distanciamento territorial".

Com base nas análises pr ecedentes, pode-se arguir que, mesmo em contextos nãosegregados espacialmente, observa-se um significativo processo de segmentação do tecido social, gerado pelo somatório da pr ofunda distância estrutural entre aqueles socialmente desiguais com uma mar cante distância r elacional entre os mesmos. E m outras palavras, apesar da pr oximidade espacial, os difer entes segmentos constituídos pela desigualdade estrutural do país se mantêm posicionados em espaços sociais relativamente segmentados, em função da profunda distância relacional entre eles.

Quais as implicações dessa combinação entr e desigualdade extrema e segmentação social para os processos organizativos? A hipótese central analisada neste ar tigo é derivada do argumento de Bourdieu, para quem

é preciso afirmar, contra o relativismo nominalista que anula as diferenças sociais ao reduzi-las a puros
artefatos teóricos, a existência de um espaço objetiv o que determina as compatibilidades e incompati-
bilidades, proximidades e distâncias. É pr eciso afirmar, contra o realismo do inteligível (ou reificação
dos conceitos), que as classes que podemos recortar no espaço social (...) não existem como gr upos re-
ais, embora expliquem a probabilidade de se constituírem em grupos práticos. (Bourdieu, 1989, p.136)

Segundo este argumento de Bour dieu, a probabilidade de mobilização e associação dos indivíduos é inversamente proporcional ao seu afastamento no espaço social. Ou seja, quanto mais afastados no espaço social, menor a pobabilidade de que os indivíduos construam relaçôes e interesses comuns que fundamentem um agir coletiv o.

Aplicando este argumento ao contexto brasileir o, marcado por desigualdades extremas, coloca-se a hipótese de que as distâncias sociais tendem a criar fores barreiras às relações entr e indivíduos e gr upos que ocupam posições distintas no espaço social. $\mathrm{N}$ a medida em que essas barr eiras bloqueiam os contatos e as $r$ elaçôes entre esses indivíduos e grupos, elas impedem a formação de $r$ edes sociais entre eles. Uma vez que, como salientam diversos autores (Diani e McAdam, 2003; Passy e Giugni, 2000; Mische, 1997), as redes sociais são a base tanto para os pr ocessos de organização quanto de ar ticulação dos atores da sociedade civil, sua inexistência tenderia a $r$ eproduzir a segmentação social no âmbito do mundo associativ o. Nesse sentido, então, sustent a-se que, no contexto de 
desigualdade estrutural e segmentação, a proximidade social tende a ser mais impor tante que a proximidade espacial na conformação das relaçōes entre as organizações constitutivas do tecido associativo, o qual tende a reproduzir a segmentação do espaço social.

\section{CARACTERIZAÇÃO DA ASSOCIAÇÃO DE MORADORES PESQUISADA}

A associação de morador es pesquisada - Associação dos Amigos e $M$ oradores do Bairro Menino Deus/ASSAMED - localiza-se no bairro Menino Deus, um dos mais antigos e tradicionais bairros de classe média de Porto Alegre, situado próximo à área central da cidade, e integrado à Região Centro do Orçamento Participativo. Segundo o Atlas do Desenvolvimento $\mathrm{H}$ umano da $\mathrm{R}$ egião $\mathrm{M}$ etropolitana de $\mathrm{P}$ orto Alegr e ( PMPA;

30 Atlas encontra-se disponível para download em: http://Iproweb.procempa.com.br/pmpa/prefpoa/observatorio/ default.php?p_secao $=115$.

4 No Atlas, a área do bairro Menino Deus está dividida entre duas UDHs, as quais ocupam a décima $(0,958)$ e a décima-segunda $(0,954)$ posição em termos de IDH.

5 Então denominada de Sociedade Amigos e Moradores do Menino Deus (SAMED).

6 Após a retomada das suas atividades, a SAMED passa a se chamar Associação dos Amigos e Moradores do Bairro Menino Deus (ASSAMED). METROPLAN; PNUD; Fundação João Pinheiro, 2008), ${ }^{3}$ o bairro possui Índice de D esenvolvimento Humano superior a 0,9 , colocando-se como uma das Unidades de Desenvolvimento Humano (UDH) com maior pontuação entre as 330 UDHs da Região Metropolitana de Porto Alegre. ${ }^{4}$ Além disso, a Região Centro do Orçamento Participativo possui o maior IDH entre todas as dezesseis regiōes da cidade $(0,919)$.

No entanto, nesta R egião encontram-se div ersas pequenas comunidades/vilas populares habitadas por populações com baixos indicadores socioeconômicos e precárias condições de urbanização. Entre estas comunidades/vilas populares, o Atlas fornece o IDH desagregado para apenas três delas:UDH Menino Deus-Condominio Lupicinio Rodrigues $(0,683)$; UDH Azenha-Vila Zero Hora (0,676); UDH Floresta-Loteamento Santa Terezinha $(0,641)$. Tais índices colocam estes locais entre as últimas $330 \mathrm{UDHs}$ do Atlas, ocupando as posições 315, 320 e 330, r espectivamente. Assim, através da comparação destes dados com os da Região e do bairro Menino Deus, identifica-se claramente a existência de um território habitado por populações que ocupam posições polar es na estrutura social da cidade.

A Associação dos Amigos e Moradores do Bairro Menino Deus ${ }^{5}$ foi fundada na década de 1970, ainda no contexto do Estado ditatorial. A iniciativa surgiu em decorrência da preocupação de alguns moradores que frequentavam uma praça do bairro (Praça Estado de Israel) com problemas de conservação urbana - tais como as más condições da iluminação, dos bueiros, das sarjetas e dos esgotos do bairr o. Entre as primeiras ações, esses moradores reivindicaram junto à Prefeitura Municipal de Porto Alegre (PMPA) a realização de obras de r evitalização da Praça Estado de Israel, obtendo sucesso no atendimento de sua demanda. Por ocasião da reinauguração da Praça, compareceram autoridades como o então prefeito nomeado G uilherme Socias Villela e o embaixador de I srael. Após essa primeira ação exitosa, tomou posse uma nova diretoria. Contudo, até 1985, a Associação esteve desativada, reiniciando suas atividades comunitárias a partir do incentivo do recém criado jornal de bairro Oi! Menino Deus.

A partir de 1986, ${ }^{6}$ a Associação passou a realizar inúmeras ações em conjunto com o jornal Oi! e com o poder público municipal. A r ealização de atividades como o "Sábado de faxina no bairr o" e o "Dia de arborização do bairr o" marcam o recomeço das atividades comunitárias. O projeto "Fala Vizinho" é outro exemplo de ação proposta pela entidade, inicialmente com a par ticipação do jornal Oi!', no intuito de identificar os pr oblemas do bairro e, por conseguinte, encaminhar as demandas à pr efeitura. Na década de 1990, destacam-se a criação do jornal da Associação (dezembro de 1990), a construção da sua sede (1994), a campanha contra a construção de um albergue municipal para moradores de 
rua (1995), a liderança na mobilização para impedir a constr ução da Pista de Eventos de Porto Alegre (popularmente conhecida como "S ambódromo") no bairr o Menino Deus (1994-1998) e a campanha de aquisição de bicicletas para policiamento comunitário no bairro (2001). A ASSAMED mantém atividades $r$ egulares, tendo as questôes $r$ elativas à (in)segurança do bairro ocupado um lugar de centralidade na atuação da entidade.

Constituída como entidade de representação dos interesses dos moradores do bairro Menino Deus, a ASSAMED expressa na composição de suas diretorias o perfil socioeconômico predominante no bairr o. Neste sentido, ao longo de toda sua história, a entidade sempre foi presidida por indivíduos socialmente posicionados no que se denominaria de "classe média": funcionários públicos, professores, comerciantes e pequenos empresários. Por outro lado, os membros da diretoria tendem, na sua grande maioria, a apresentar formação de nível superior, com a presença de vários indivíduos com pós-graduação.

\section{AS RELAÇÕES DA ASSAMED}

Uma das formas de identificar os efeitos da desigualdade sobr e o tecido associativo é observar as relações que as organizações estabelecem entr e si. Nesse sentido, esta seção utiliza duas fontes de dados para identificar as $r$ elações da ASSAMED com outras entidades da sociedade civil por to-alegrense. A primeira fonte é constituída pelas $r$ espostas da entidade a um survey realizado com 167 associaçóes de moradores de Porto Alegre no ano de $2003 .{ }^{7}$ Neste survey, as entidades foram questionadas sobre as relações que elas possuíam com outras entidades, e as respostas obtidas junto a ASSAMED permitem identificar a seguinte rede de contatos:

Figura 1 - Relações da ASSAMED com outras associações de morador es

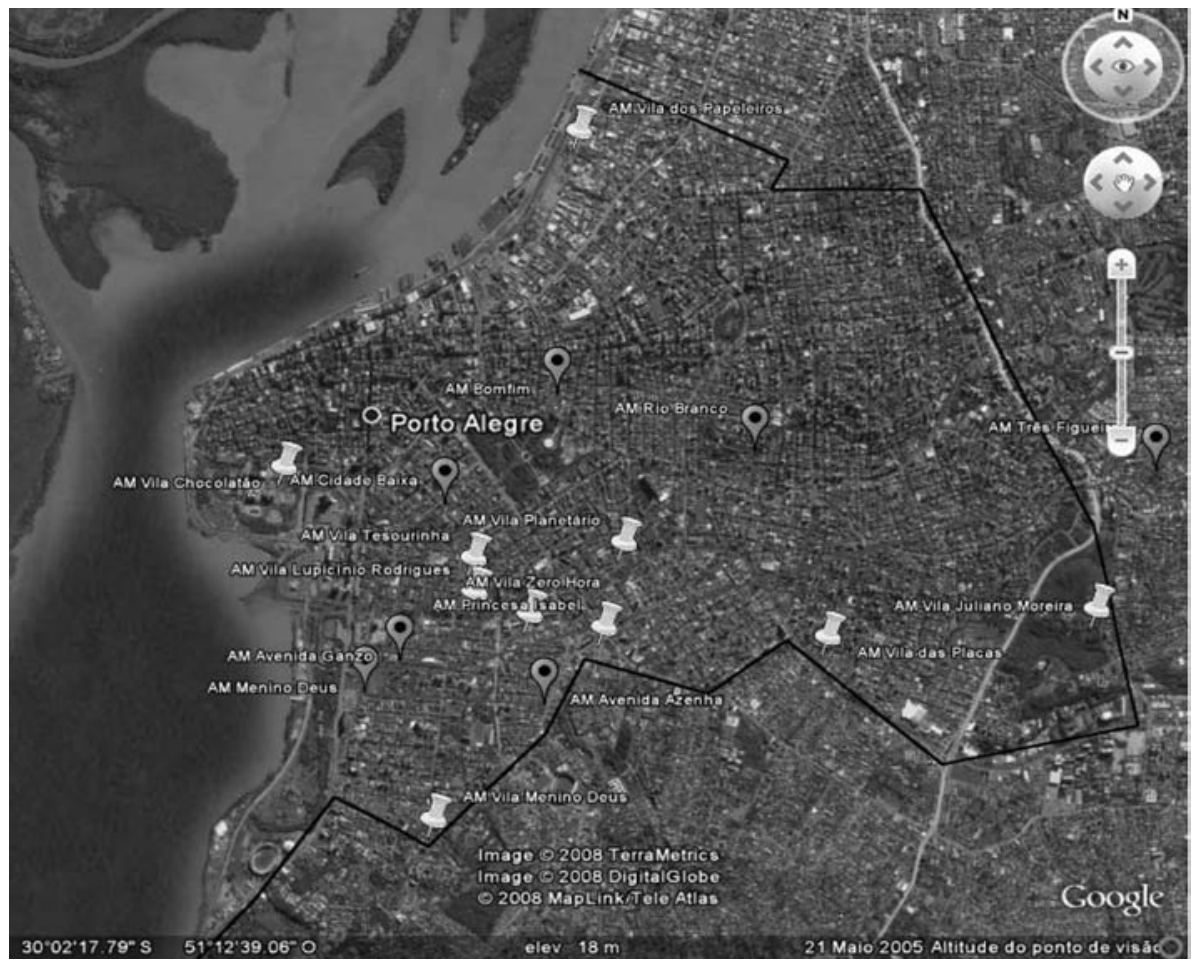

Fonte: Survey Associaçóes de Moradores de Porto Alegre/2003.
7 Os dados e a análise desta pesquisa encontram-se disponiveis em: http://pr o web.procempa.com.br/pmpa /prefpoa/observatorio/ usu_doc/relatorio_final_ mapa_associativismo.pdf. 
8 Isto não significa que, eventualmente, não tenham ocorrido $r$ elações entr e a ASSAMED e membr os destas outras associações populares. Ao contrário, na pesquisa documental $r$ ealizada no jornal da entidade foram coletadas informações sobr e a ocorrência deste tipo de $r$ elações. No entanto, estes vínculos tendem a ser pontuais e a não constituir uma rede mais sólida e permanente.

De acordo com esta imagem, percebe-se que a ASSAMED tende a restringir seus contatos (assinalados com marca escura) às entidades situadas em bairros de classe média e alta. Todas as seis associações de morador es referidas na entrevista da ASSAMED são entidades que r eúnem e representam interesses de segmentos ocupantes de posições superior es na estrutura social de Porto Alegre. Nesse sentido, praticamente todas elas situam-se entre os vinte bairros com os melhores indicadores socioeconômicos da cidade (PMPA, 2007).

Por outro lado, observa-se a não referência à existência de vínculos entre a ASSAMED e as associações de morador es das vilas popular es localizadas na R egião Centro de Porto Alegre, identificadas com mar ca clara na imagem. A pesar de várias destas associações apresentarem significativa proximidade espacial em relação à ASSAMED, não foi informado nenhum tipo de vínculo entre elas. ${ }^{8}$

Uma segunda fonte de informações para caracterizar as $r$ elaçóes estabelecidas pela ASSAMED é fornecida pelo site do Movimento Porto Alegre Vive. Este movimento foi formado por uma articulação de entidades que começou a se constituir na década de 1990, tendo como uma de suas principais ações a defesa da qualidade de vida dos bairr os "nobres" de Porto Alegre frente ao avanço das grandes edificações e da especulação imobiliária. A par tir de dados coletados no blog do movimento (http://poavive.wordpress.com), em 2008, observa-se a inserção da ASSAMED na seguinte rede de entidades:

Figura 2 - Entidades participantes do Movimento Porto Alegre Vive

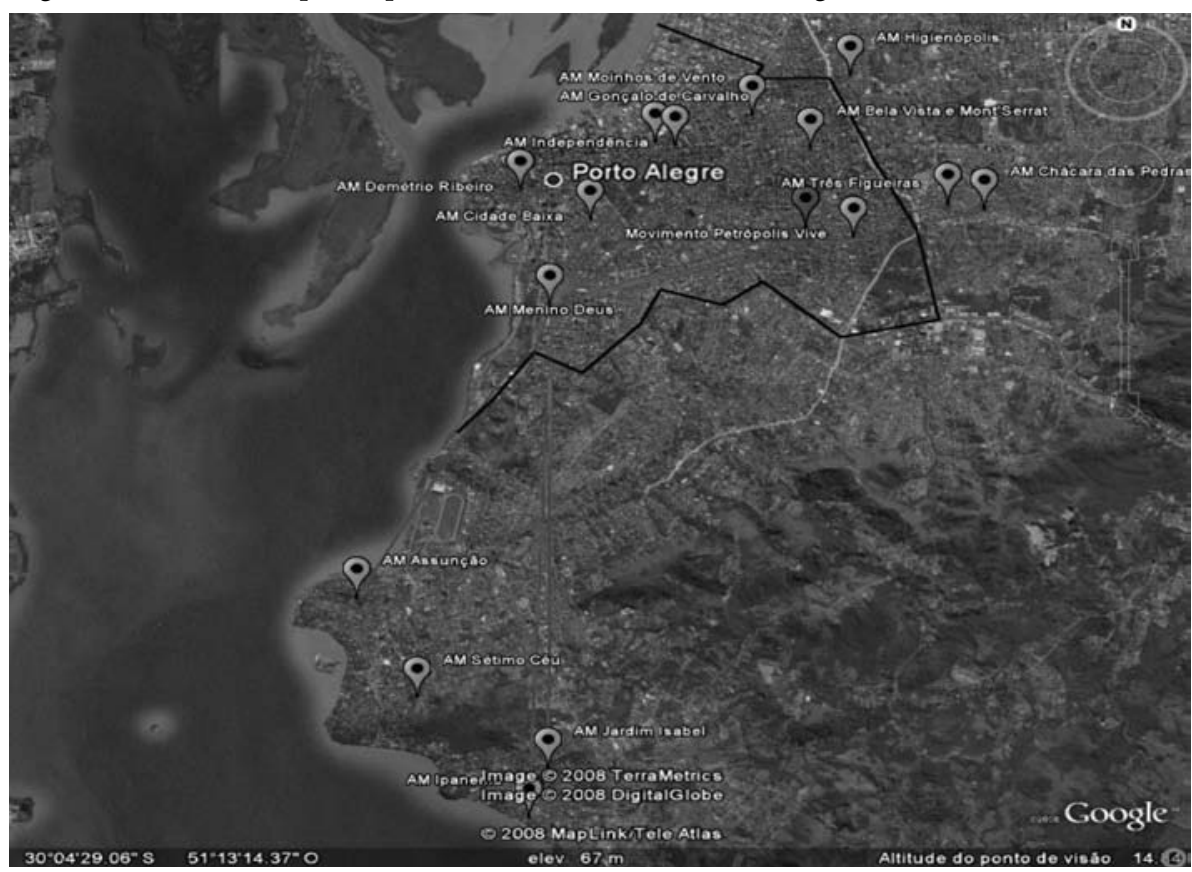

Fonte: http://poavive.wordpress.com.

Novamente, os dados confirmam a for te tendência da ASSAMED a restringir seus vínculos a organizações constituídas por segmentos das classes médias e altas da cidade. Isto se expressa no fato de que, das quinz e entidades referidas no site do Movimento no período da coleta de informações, nada menos do que onz e delas se situav am nos vinte bairros com melhor es indicador es socioeconômicos. Além disso, todas elas situav am-se nas UDHs com os maiores índices de desenvolvimento humano da cidade, conforme indica o mapa abaixo: 
Figura 3 - Unidades de Desenvolvimento Humano de Porto Alegre segundo o Índice de Desenvolvimento Humano Municipal, 2000

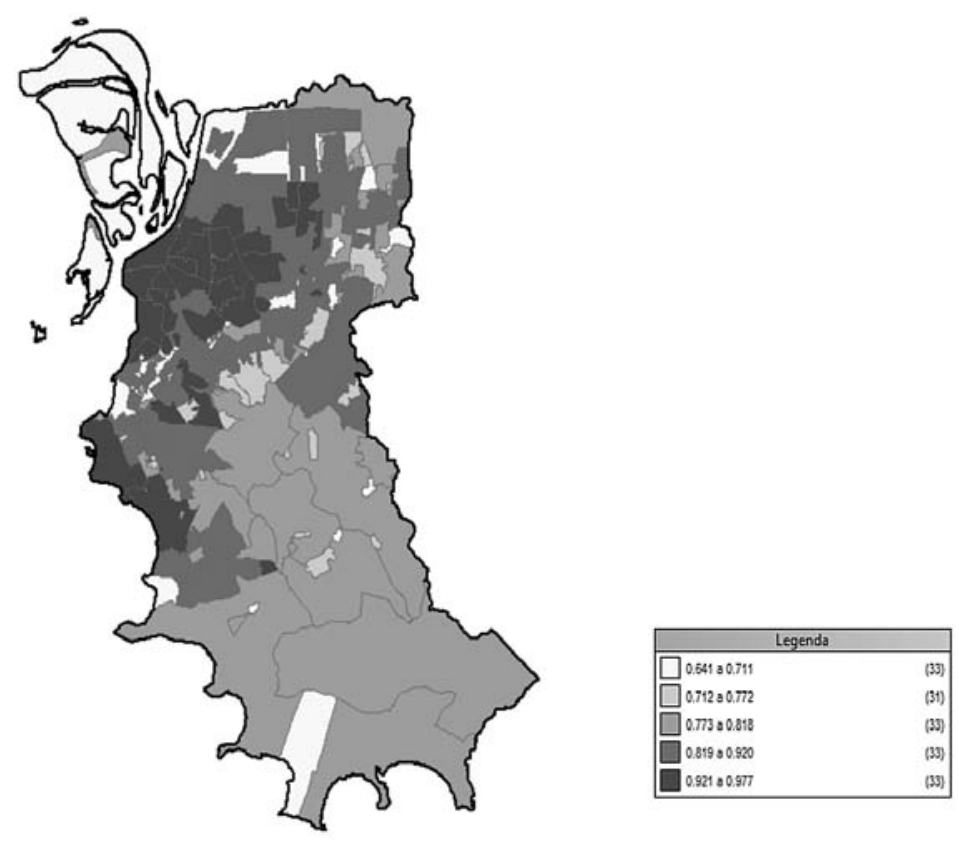

Fonte: PMPA; Metroplan; PNUD; Fundação João Pinheiro, 2008.

Essas duas fontes mostram, assim, a tendência de que as distâncias sociais se $r$ eproduzam na conformação da rede associativa na qual a ASSAMED se integra e, de forma mais geral, no tecido associativo da cidade, fazendo com que as organizações restrinjam seu leque de relações àquelas constituídas pelos segmentos ocupantes de posiçóes similar es na estrutura social. Em vista disso, parece se confirmar a hipótese de que a pr oximidade social, ao invés da pr oximidade espacial, tende a ser o fator central na definição das possibilidades de relacionamento entre as organizaçóes.

\section{A ATUAÇÃO DA ASSAMED: A DISPUTA SOBRE A PISTA DE EVENTOS - 1994 -1998}

Da mesma forma que a análise das r elações estabelecidas pela ASSAMED indica uma forte tendência à homofilia - ou seja, ao r elacionamento com iguais -, o estudo da atua ção da entidade permite chegar a uma conclusão similar . Para ilustrar esse argumento, analisa-se nesta seção uma das ações mais impor tantes na história da ASSAMED: a luta vitoriosa contra a constr ução da Pista de Eventos, popularmente denominada de "S ambódromo", em uma área do bairro.

Em meados da década de 1990, na gestão deTarso Genro (PT), a Prefeitura de Porto Alegre iniciou o projeto de construção da Pista de Eventos, pensada como um espaço para sediar as manifestações culturais populares da cidade (entre elas, os desfiles carnavalescos). Inicialmente, o Executivo municipal tentou implantar a obra junto ao Parque Maurício Sirotsky Sobrinho, também conhecido como $\mathrm{P}$ arque da $\mathrm{H}$ armonia, localizado na área central da cidade. Essa tentativ a sofreu fortes críticas de integrantes do $\mathrm{M}$ ovimento Tradicionalista Gaúcho (MTG), ${ }^{9}$ de ambientalistas, do prefeito antecessor e de vereadores
90 MTG organiza anualmente, no mês de setembr o, o chamado Acampamento Farroupilha no Par que da Har. monia. Este Acampamento comemora a Revolução Far roupilha (1835-1845) e r eúne milhar es de pessoas. Além disso, o parque possui equipamentos públicos utili zados pelo MTG. 
10 Numa primeira ação, foi enviado à Câmara de Vereadores um abaixo-assinado com mais de 500 assinaturas de moradores do Menino Deus manifestando-se contra o novo local de instalação da Pista de Eventos. Posteriormente à ação judicial no Ministério Público, a associação coletou apr oximadamente mais 3000 assinaturas.

11 Segundo informações encontradas no Jornal da ASSAMED de maio de 2002, foram gastos apr oximadamente 30 mil $r$ eais em ações contra a implantação da Pista de Eventos.
$\begin{array}{lllllllllllllllllllllllllll}D & E & S & I & G & U & A & L & D & A & D & E & E & A & S & S & O & C & I & A & T & I & V & I & S & M & O\end{array}$

(inclusive de alguns integrantes da bancada petista). Em fins de 1994, o projeto foi rejeitado pela Câmara de Vereadores. Contudo, o governo municipal não desistiu do projeto, propondo, então, um novo local, dessa vez junto ao estádio Beira-Rio, do Sport Club Internacional, ao lado do Parque Marinha do Brasil.

A nova localização da Pista de Eventos, no interior do bairro Menino Deus, provocou forte reação de inúmeros agentes e instituições ali situadas, destacando-se o $\mathrm{H}$ ospital Mãe de Deus, o Asilo Padre Cacique, a Fundação Estadual do Bem Estar do Menor (FEBEM), clínicas geriátricas, morador es, escolas circundantes e associações de moradores de bairro. A ASSAMED, em especial, teve atuação marcante nas açôes contra a construção da Pista de Eventos. De fato, pode-se afirmar que ela ocupou uma posição de centralidade em tal processo, realizando vários abaixo-assinados, ${ }^{10}$ promovendo assembleias comunitárias na sua sede e na Escola Estadual P residente Roosevelt, publicando no seu jornal ar tigos de morador es e de v ereadores contrários à instalação do $S$ ambódromo, contatando e mobilizando v ereadores e, ainda, encaminhando uma ação no $\mathrm{M}$ inistério Público. Além disso, a entidade angariou fundos monetários para sustentar sua campanha pública, sendo que, no período entr e novembro de 1997 e janeir o de 1998, os entrevistados informaram que foram arr ecadados e gastos mais de $17 \mathrm{mil} \mathrm{r}$ eais em ações contra a Pista de Eventos. ${ }^{11}$

A rede de atores mobilizados pela ASSAMED durante as ações contrárias à construção da Pista de Eventos, apresentada na Figura 4 abaixo, demonstra uma significativa capacidade de mobilizar agentes internos e agentes externos à comunidade do bairr o Menino Deus. Ou seja, tais informaçóes mostram a existência de um significativo estoque de "capital social" detido pela ASSAMED, o qual foi mobilizado tanto para a arrecadação dos recursos necessários para manutenção da campanha contra a P ista de Eventos quanto para a confrontação com o governo municipal em diversas frentes (Executivo, Legislativo, Judiciário, Imprensa, bairro etc.).

Figura 4 - A rede de atores e ações no processo de contestação da construção da Pista de Eventos no bairro Menino Deus

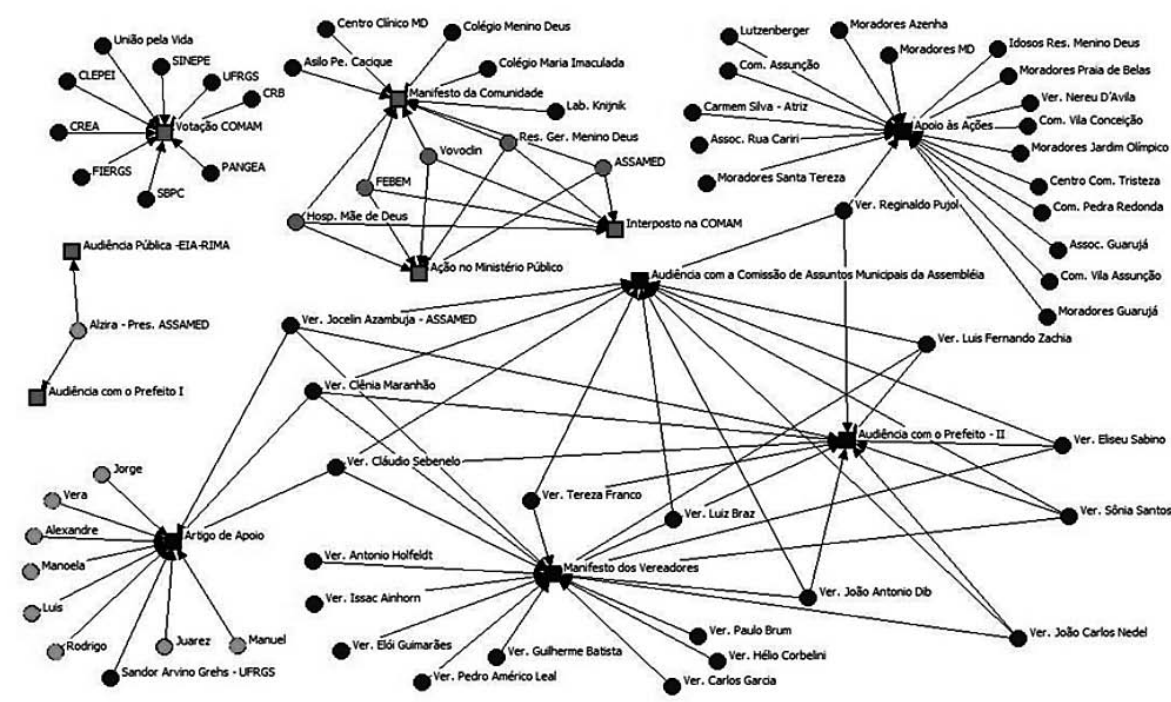

Fonte: Elaboração dos autores a partir do material coletado. 
Os dados acima mostram, em primeiro lugar, que a ASSAMED recebeu apoio de parcela significativa dos vereadores de Porto Alegre, demonstrando sua capacidade de mobilizar atores em posição de autoridade para o suporte de sua posição. Isso fica evidenciado quando se observa a estruturação de vínculos com dezenove vereadores, que participaram em difer entes ev entos, ar ticulaçōes e manife staçōes (assinaladas por quadrados de cor escura) promovidas pela entidade. Além disso, os v ereadores se manifestaram publicamente por meio de " $\mathrm{M}$ anifesto em apoio às $\mathrm{r}$ eivindicaçōes da comunidade do $\mathrm{M}$ enino Deus", bem como escrevendo artigos no jornal da Associação. ${ }^{12}$

É preciso destacar, em particular, a atuação do vereador Jocelin Azambuja, que, naquele período, também era dir etor do departamento jurídico da ASSAMED. Este vínculo mostra a "riqueza" do capital social acumulado pela Associação, que podia contar entr e seus quadros com pessoas em posiçóes de autoridade e, assim, com os recursos associados a essas posições. Nesse sentido, o vereador viabilizava um mecanismo fácil e eficaz de conexão entre a Associação e setor es oposicionistas da Câmara de Vereadores de Porto Alegre, através das redes de relações pessoais previamente constituídas.

Outro grupo importante de ator es mobilizado na oposição à P ista de Eventos era constituído por div ersas instituiçóes localizadas no bairr o. Conforme informaçóes pr esentes no jornal da Associação, um grupo de nove instituições, após participação em audiência pública na qual ficou evidente a posição do Executivo municipal em construir o Sambódromo ao lado do P arque Marinha do B rasil, decidiu manifestar publicamente seu apoio às ações já desencadeadas pela ASSAMED. Assim sendo, produziu-se um documento expondo o posicionamento desse gr upo, assinalado pelas instituições ligadas ao "nó" Manifesto da Comunidade na F igura 4. Posteriormente, esses atores participaram de reunião no Conselho Municipal do Meio Ambiente, cuja pauta foi o processo de licenciamento do local de implantação da lista de Eventos e o recurso interposto por essas instituições.

As ações e manifestações do núcleo central da mobilização contra a P ista de Eventos, cuja liderança coube à ASSAMED, tiveram ainda o apoio de outras associações de moradores, grupos de moradores e personalidades externas ao bairro Menino Deus. Esses indivíduos, grupos de indivíduos e entidades foram integrados na rede de relacionamentos, na medida em que foram citados no jornal da Associação, ealizaram alguma atividade em conjunto com ela ou, ainda, expr essaram o seu apoio às açóes contrárias ao pr ojeto do Executivo municipal. Na sua maioria, esses atores representam ou integram uma população situada nos segmentos médios e altos da cidade de P orto Alegre.

É interessante observar que, enquanto ocorria esta intensa mobilização e articulação contra a Pista de Eventos entre os segmentos médios e altos, paralelamente se pr oduziu uma articulação em defesa da Pista de Eventos, constituída unicamente pelas associaçóes de moradores das vilas populares localizadas no bairro Menino Deus ou no seu entorno. Esta articulação pró-Pista de Eventos se expressa, por exemplo, no documento "Manifesto Cultural: Menino Deus quer a P ista de Eventos", assinado pelas seguintes entidades: Associação Vila das Placas, Associação dos Moradores da Vila Zero Hora, Associação dos Moradores da R enascença I, Associação da Vila Lupicínio Rodrigues e Associação dos Moradores da Luiz Guaranha.

Neste manifesto, as entidades popular es afirmam, de um lado, o seu apoio a um projeto que propiciaria um espaço adequado para as expr essóes culturais "legítimas" da população, tal como se expr essa na seguinte colocação: "Teremos em br eve a P ista de Eventos porque nós merecemos, pois não fazemos barulho. Nós fazemos música, nós fa-
12 No jornal da ASSAMED de outubro de 1997 encontram-se os textos: "Pista de Eventos não!", de Jocelin Azambuja; "Menino Deus quer ser ouvido", de Claudio Sebenelo; e "A par ticipação da comunidade", de Clênia Maranhão. No jornal da ASSAMED de março de 1998 encontra-se o ar tigo "T odo Poder emana do povo", de Jocelin Azambuja. 
zemos ar te!". De outro lado, estas entidades também se contrapõem ao argumento da ASSAMED de que o pr ojeto seria uma imposição do go verno municipal, ao salientar em que teriam participado da discussão e decisão sobre este projeto no âmbito do Orçamento Participativo, ao mesmo tempo que fica subentendido no manifesto uma crítica à não participação da ASSAMED (tema analisado na próxima seção). Este movimento de suporte à Pista de Eventos, no entanto, não tev e forças para se contrapor à ampla e poder osa mobilização capitaneada pela ASSAMED contra a Pista de Eventos, a qual acabou sendo vitoriosa no seu embate contra a P refeitura, que transferiu o projeto para uma ár ea periférica da cidade.

A mobilização contra a Pista de Eventos mostra que a ASSAMED contava com uma significativa rede de relações com indivíduos, entidades e instituições pertencentes aos estratos superiores da cidade, passível de ser mobilizada na defesa de seus inteesses. Ao mesmo tempo, permite identificar uma clara divisão do tecido associativ o em função de posicionamentos sociais distintos. $\mathrm{D}$ e um lado, a coalizão capitaneada pela ASSAMED, voltada a defender a "qualidade de vida" do bairro contra uma ação do go verno municipal que, conforme texto publicado no jornal da ASSAMED (outubro/1997), iria "transtornar a vida da comunidade" do Menino Deus. De outro, a ar ticulação das entidades populares, defendendo uma obra que, além de criar um espaço para manifestações culturais valorizadas pelos moradores das vilas populares, também geraria oportunidades de renda para estas populações (como argumentavam em seu manifesto).

\section{DESIGUALDADES E ORÇAMENTO PARTICIPATIVO}

13 Esta tendência de predomínio dos segmentos populares no OP se expr essa claramente nos dados de renda dos par ticipantes do OP/2005: enquanto $49,8 \%$ tinham renda familiar até 2 salários-mínimos $(31,1 \%$ na população da cidade), somente $3,4 \%$ tinham $r$ enda familiar maior de 12 saláriosmínimos $(16,5 \%$ na populacão da cidade) (Fedozzi, 2007, p.19).
Por fim, para apr eender como a desigualdade se manifesta na dinâmica associativ a, é importante analisar a r elação da ASSAMED com um espaço institucional que, nas últimas décadas, se converteu no centro da atuação de grande parte das associações de moradores de Porto Alegre (Silva, 2007): o Orçamento Participativo (OP).

Instituído com o objetiv o de "inverter prioridades" na alocação dos inv estimentos municipais, o OP de Porto Alegre se configura, atualmente, como um espaço de participação, sobr etudo, para as camadas popular es. Um simples olhar, por ex emplo, nas reuniōes do Fórum da Região Centro evidencia a presença, na sua grande maioria, de indivíduos oriundos de vilas e comunidades popular es. Além disso, quando analisamos as prioridades eleitas por essa região nos anos de 2007, 2008 e 2009, a categoria habitação aparece sempre em primeiro lugar, revelando a regularização fundiária e a construção de moradias como as principais demandas dos gr upos que par ticipam do OP na Região Centro. Na medida em que, conforme dados apr esentados anteriormente, esta é a r egião com melhor IDH na cidade, a priorização de demandas de $\mathrm{r}$ egularização fundiária e urbanização indica que são os setor es mais pauperizados da r egião que tendem a intervir no OP. ${ }^{13}$

Estudos sobre a participação da sociedade civil no OP tiveram como objeto de análise, na maioria dos casos, associaçôes de morador es representantes de gr upos populares (Abers, 2000; Silva, 2002). Assim, tanto a par ticipação quanto a per cepção das associações de moradores de classe média em r elação ao OP é praticamente desconhecida. Uma breve reconstrução histórica do env olvimento da ASSAMED nesse espaço de par ticipação expóe aspectos relevantes para pensarmos as possív eis relaçóes entre associativismo, desigualdade e o OP. 
Já em 1989, ano da implementação do OP em Porto Alegre, a ASSAMED esteve envolvida no seu processo de construção. Através do for te vínculo com o jornal Oi! Menino Deus, ${ }^{14}$ a ASSAMED, de certo modo, contribuiu para a publicização da iniciativa do governo municipal, convidando a população do bairr o a participar ativamente. $\mathrm{O}$ levantamento das prioridades definidas pela população foi uma das primeiras ações; posteriormente, um representante da entidade entregou a lista de reivindicações à Prefeitura, a fim de que fosse integrada ao orçamento municipal do ano seguinte. $\mathrm{N}$ o entanto, em fins de 1990, uma acirrada e conflituosa eleição para a dir eção da entidade pr ovocou o rompimento da relação entre o jornal Oi! e a ASSAMED. A nova diretoria, então, inaugurou seu próprio jornal comunitário, em de zembro de 1990.

A relação entre o jornal Oi! e a ASSAMED permaneceu conflituosa. E m meados de 1991, noticiando uma situação em que a diretoria da Associação abandonou uma assembleia do OP, o jornal acusou a entidade de não participar das discussóes sobre o orçamento municipal. A diretoria da ASSAMED se justificou afirmando que houve falha no processo de $r$ epresentação, pois anteriormente havia sido informada que a entidade seria representada por dois delegados e um suplente e, na assembleia, the coube apenas uma suplência na chapa v encedora. Com isso, a r epresentação do bairro ficou a cargo de um membro do jornal $\mathrm{O} i$ ! presente na reunião. Apesar desses contratempos, a ASSAMED permaneceu na $r$ eunião e entr egou a sua lista de $r$ eivindicações dir etamente ao pr efeito. Posteriormente a esses fatos, o Oi! realizou algumas r euniōes comunitárias para lev antar as prioridades do bairro, e a ASSAMED se defendeu das acusações do Oi! através de seu recém-criado jornal.

As discussões entre o jornal $O i$ ! e a ASSAMED sobre a participação desta no OP continuaram no ano de 1992. Enquanto o primeiro reforçava a ausência da Associação nas reuniōes, esta se defendia e informava que "através dos números de nossas publicações e algumas comunicações em rádio e TV, é possível aos interessados saber o que é feito por nós, inclusive por ocasião do $\mathrm{O}$ rçamento Participativo/92, que entr egamos por escrito, e está incluído no relatório apresentado na câmara municipal, em 08/04/92" (Jornal Oi! Menino Deus, agosto, 1992). Nos anos seguintes, a ASSAMED informou sobre a sua presença nas reuniões mensais do OP, salientando, em meados de 1994, algumas conquis tas do bairro, tais como: pavimentação de r uas, iluminação de praças e melhoras no sa neamento básico. Entretanto, não informava como se dava a sua atuação no processo.

Em 1995, a constr ução de um albergue para morador es de $r$ ua no bairr o Menino Deus lev ou a ASSAMED a mobilizar seus vínculos com v ereadores, sobr etudo J ocelin Azambuja, morador do bairro, a fim de acessar os agentes públicos responsáveis pela obra e expressar a sua contrariedade quanto à localização do albergue. $O$ OP foi um desses espaços, porém, de acordo com o jornal da entidade, o seu coor denador regional não estava a par do assunto, e a orientou a pr ocurar o prefeito, o qual não respondeu às suas solicitações. A par tir de então, a Associação começou manifestar duras críticas ao go verno municipal, e o OP foi tachado como uma farsa. Isso porque, segundo a entidade, mesmo que tenha participado das reuniōes do OP desde 1991, ela nunca foi consultada sobr e a construção do albergue. No ano de 1996, com o albergue em funcionamento, o jornal da entidade manifestou os problemas que os moradores do bairro passaram a enfrentar. Duas dessas reportagens tinham como título: "U m albergue a céu aber to" e "Menino Deus invadido pelos moradores de rua".

Vale ressaltar que, diante das inúmeras dificuldades em barrar a constução do albergue, a Associação se v aleu de seus laços sociais com v ereadores para se manifestar publi -
14 Este jornal de bairro era publicado por um jornalista com posições políticas pr ogressistas e que integrava a direção da ASSAMED. 
camente sobre o assunto. A sua tentativa de utilizar o OP como espaço de intermediação fracassou, o que a levou a fazer pesadas críticas ao governo municipal e ao próprio OP. Fato semelhante aconteceu em meados de 1997, no auge da luta contra a P ista de Eventos no Menino Deus. Um texto publicado no jornal da Associação criticav a severamente o governo municipal, em especial, o aumento do IPTU e o OP, o qual foi qualificado como "uma farsa já descoberta, pois as pessoas ligadas à Prefeitura têm maior poder de voto que as pessoas da comunidade, que são em menor número para votarem. A comunidade acha que resolve alguma coisa, mas já v em tudo pronto dos gabinetes" (Jornal da ASSAMED, outubro, 1997).

Nos anos de 2000 e 2001, a Associação destaca sua presença constante no OP, mencionando no seu jornal a periodicidade das $\mathrm{r}$ eunióes e enfatizando a necessidade da ampliação da pr esença dos morador es do $\mathrm{M}$ enino $\mathrm{D}$ eus. Contudo, as mençôes sobr e as reuniōes não revelam manifestaçóes concretas nem os objetivos e as prioridades da Associação nesse espaço. Nos anos de 2002 e 2003, não se encontram mais r eferências à participação da ASSAMED nas reuniões do OP.

Inicialmente, apresentamos o OP como que configurado pelas camadas popular es, ou seja, um espaço de par ticipação da sociedade civil junto ao Estado no qual pr edomina a atuação de comunidades e vilas cujos indivíduos se encontram numa posição social desfavorecida. Seria, então, o OP um "espaço dos pobres", enquanto as classes médias utilizariam outras formas de atuaçãa? A despeito da ASSAMED buscar demonstrar continuamente a sua presença no OP, as suas principais ações e manifestaçóes no período analisa do - construção da sede, as mobilizaçóes contra a Pista de Eventos e o albergue municipal e a aquisição de bicicletas para o policiamento do bairı - foram conduzidas longe do OP, através de outros recursos e modelos de atuação comunitária.

\section{CONSIDERAÇÕES FINAIS}

Mesmo tendo presente as limitações inerentes a um estudo de caso realizado no contexto de uma cidade particular, os resultados da pesquisa realizada junto à ASSAMED trazem conclusões que problematizam as visões homogeneizadoras e, especialmente, apolo géticas sobre a sociedade civil. A o contrário destas visões, obser va-se a existência de um denso tecido associativ o mar cado pelas desigualdades constitutiv as da sociedade na/da qual se originou. $\mathrm{M}$ ais especificamente, obser va-se uma segmentação da vida associativ a a partir de recortes socioeconômicos, que reproduz as significativas distâncias estruturais e relacionais que caracterizam e sustentam as extr emas desigualdades do país.

Este resultado é particularmente relevante quando se tem presente que esta segmentação ocorre em uma cidade que se caracteriza por uma longa e rica história associativ a, na qual os segmentos popular es foram capazes de constr uir formas de ação coletiv a que lhes conferiu r elevância na dinâmica política municipal. Além disto, esta segmentação tende a se manter, a despeito da introdução de uma série de mecanismos de par ticipação institucional, entre os quais, destaca-se o OP.

Tais conclusões colocam a necessidade de uma complexificação dos modelos teóri cos de análise dos processos associativos, introduzindo, entre outros aspectos, a desigualdade como uma dimensão fundamental para a adequada interpr etação destes processos em países como o B rasil. Assim, poder-se-ia abor dar analiticamente as especificidades das configurações associativ as brasileiras, sem $\mathrm{r}$ ecorrer às tradicionais perspectiv as que 
avaliam (e, em geral, condenam) tais configurações a par tir da métrica fornecida pela universalização de processos característicos de outros contextos sociais menos desiguais. Esta atenção analítica para as especificidades dos contextos empíricos permitiria romper com aquilo que Chatterjee denomina de "universalização do provincianismo ocidental", segundo o qual:

o provincianismo da experiência eur opeia será tomado como a história univ ersal do pr ogresso; por comparação, a história do resto do mundo irá aparecer com a história da falta, da inadequação - uma história inferior . Apelos serão feitos no vamente às filosofias pr oduzidas na Inglaterra, França e Alemanha. O fato de que estas doutrinas foram produzidas em completa ignorância de outras par tes do mundo não impor tará: elas serão consideradas úteis e iluminadoras. (Chatterjee, 1990, pp.131-2)

\section{REFERÊNCIAS BIBLIOGRÁFICAS}

ABERS, R. Do clientelismo à cooperação: governos locais, políticas participativas e organização da sociedade civil em Porto Alegre. Porto Alegre, Cadernos da CIDADE, n.7, v.5, maio 2000.

ALONSO, J. A. F. et al. Território, economia e sociedade: transformaçōes na Regiāo Metropolitana de Porto Alegre. Porto Alegre: FEE, 2009.

BOTTERO, W. Stratification: social division and inequality . London: R outledge, 2005.

BOURDIEU, P. O Poder Simbólico. Lisboa: Difel/Bertrand, 1989.

CALDEIRA, T. P. A politica dos outros. São Paulo: Brasiliense, 1984.

. Cidade de mur os: crime, segr egação e cidadania em São P aulo. São Paulo:

Edusp, 2000.

CHATTERJEE, P. A response to Taylor's "Modes of Civil S ociety". Public Culture, n.1, v.3, pp.119-132, fall 1990.

DIANI, M.; McADAM, D. (eds.). Social movements and networks: relational approaches to collective action. Oxford: Oxford University Press, 2003.

DREIFUSS, R. A. A conquista do Estado: ação politica, poder e golpe de classe . Petrópolis: Vozes, 1981.

DREIFUSS, R. A. O Jogo da direita na Nova República. Petrópolis: Vozes, 1989.

FEDOZZI, L. J. Observando o O rçamento Participativo de P orto A legre. Porto Alegr e: Tomo Editorial, 2007.

FERREIRA, M. C. “ Associativismo e contato político nas R egiōes Metropolitanas do Brasil: 1988-1996 - r evisitando o problema da participação”. Revista Brasileira de Ciências Sociais, São Paulo, n.41, v.14, pp. 90-102, outubro 1999.

IBGE; IPEA; ABONG; GIFE. As fundaçōes privadas e associações sem fins lucr ativos no Brasil. Rio de Janeiro: IBGE, 2008.

KERSTENETZKY, C. L. Sobre associativismo, desigualdades e democracia. Revista Brasileira de Ciências Sociais, São Paulo, n.53, v.18, pp.131-42, 2003.

KOWARICK, L. A espoliação Urbana. Rio de Janeiro: Paz e Terra, 1979.

LAVALLE, A. G. Sem pena nem glória: o debate sobr e a sociedade civil nos anos 1990. Novos Estudos, São Paulo, n.66, p. 91-109, julho 2003.

MARQUES, E. C. R edes sociais e instituições na constr ução do Estado e da sua per-
Marcelo Kunrath Silva

é bacharel em História (UFRGS/1989), mestr e em Sociologia (UFRGS/1997), doutor em Sociologia (UFRGS/2001), com pósdoutorado na Brown University (2008). É pr ofessor do Departamento de Sociologia e do Pr ograma de PósGraduação em Sociologia/ UFRGS, coor denador do Programa de Pós-Gradua . ção em Sociologia/UFRGS. Email: mksilva@ufrgs.br.

Rui Zanata Jr . é licenciado em Ciências Sociais (UFRGS/2008), bacharelando em Ciências Sociais (UFRGS) e bolsista de Iniciacão Científica (CNPq/ UFRGS). Email: ruizanatajr @yahoo.com.br.

Artigo r ecebido em setem bro de 2009 e aprovado para publicação em janeiro de 2010. 
meabilidade. Revista Brasileira de Ciências Sociais, São Paulo, n.41, v.14, pp.45-67, outubro 1999.

MARQUES, E. C. et al. Redes sociais e pobr eza. Trabalho apr esentado no E ncontro Anual da ANPOCS, 2007. (D isponível em: http://www.centrodametropole.org.br/pdf/ 2007/Anpocs2007ColetivoFinal.pdf)

MISCHE, A. D e estudantes a cidadãos: $r$ edes de jo vens e par ticipação política. Revista Brasileira de Educação, n.5/6, pp.134-50, 1997.

PASSY, F; GIUGNI, M. Life-S pheres, Networks, and S ustained Participation in S ocial Movements: A P henomenological A pproach to P olitical Commitment. Sociological Forum, n.1, v.15, pp.117-44, 2000.

PMPA. Mapas e indicadores das vulnerabilidades sociais. Porto Alegre: PMPA, 2007.

PMPA; Metroplan; PNUD; Fundação João Pinheiro. Atlas do desenvolvimento humano da regiāo metropolitana de Porto Alegre. Porto Alegre: PMPA, 2008.

REIS, E. Pobreza, desigualdade e identidade política. In: DINIZ, Eli (org.). O desafio da democracia na América Latina (Anais do seminário). Rio de Janeiro: IUPERJ, 1996.

RIBEIRO, L. C. de Q. P roximidade territorial e distância social: r eflexóes sobre o efeito do lugar a par tir de um enclave urbano. Revista VeraCidade, Salvador, Ano 3, n.3, pp.121, maio 2008.

SANTOS, W. G. Horizonte do desejo: instabilidade, fracasso coletivo e inércia social. $2^{\mathrm{a}} \mathrm{ed}$. Rio de Janeiro: FGV Editora, 2006.

SILVA, L. S. da et al. Segregação r esidencial e r elações de vizinhança no bairr o de Apipucos (R ecife-PE). In: S impósio N acional de G eografia U rbana. F lorianópolis: X SIMPURB, 2007. D isponível em: http://www .observatoriodasmetropoles.ufrj.br/Segre ga_Residencial.pdf. Acesso em: 03 de junho de 2009.

SILVA, M. K. M apa do Associativismo de P orto Alegr e. 2007 D isponível em: http://lproweb.procempa.com.br/pmpa/prefpoa/observatorio/usu_doc/relatorio_final _mapa_associativismo.pdf. Acesso em: 05 de janeiro de 2010. Sociedade Civil e Constr ução Democrática: do maniqueísmo essencialista à abordagem relacional. Sociologias, Porto Alegre, v.8, pp.156-79, 2006.

Cidadania e exclusão. Porto Alegre: Editora da Universidade Federal do Rio Grande do Sul, 2002.

SILVA, M. G. B. da; BIT OUN, J. A uto-segregação no espaço periférico entr e Recife e Olinda. Revista de Geografia, Recife, v.23, n.1, 2006.

TORRES, H. da G. S egregação residencial e políticas públicas: São P aulo na década de 1990. Revista Brasileira de Ciências Sociais, São Paulo, n.54, v.19, pp.41-55, fev. 2004.

TORRES, H. da G. et al. Pobreza e espaço: padrões de segregação em São Paulo. Estudos Avançados, São Paulo, n.47, v.17, pp.97-128, 2003.

A B S T R A C T The aim of this paper is to analyz e how the great inequalities of Brazilian society affects on the confor mation of associational life in the big cities, based on a empirical $r$ esearch with an $N$ eighborhood $A$ ssociation of a tr aditional middle-class neighborhood of Porto Alegre. From the study of relations and the action of this entity, we can see a high degr ee of segmentation of the social fabric of the city as a $r$ esult of the mar ked structural and $r$ elational distances betw een its $r$ esidents. Because of this segmentation, the associations of middle and upper classes tend to establish links and develop actions with actors who share similar positions in social space. A t the same time, they do not tend to $r$ elate to 
M A R C E L O K U N R A T H S I L V A, R U I Z A N A T A J R

popular organizations, even though spatially close. These results indicate that inequalities tend to reproduce in the associative processes that make up the Brazilian civil society a subject narely discussed in the literature on the topic.

K E Y W O R D S Association; civil society; inequality; social distance; Porto Alegre. 